\title{
Prevalence of Self-medication Practices for Oral Health Problems among Dental Patients in a dental college: A Descriptive Cross-sectional Study
}

\author{
Rosina Bhattarai, ${ }^{1}$ Sunita Khanal, ${ }^{2}$ Sujita Shrestha ${ }^{2}$ \\ 'Department of Community Dentistry, College of Medical Sciences, Bharatpur, Chitwan, Nepal, ${ }^{2}$ Department of Community \\ Dentistry, Kantipur Dental College, Dhapasi, Kathmandu, Nepal.
}

\begin{abstract}
Introduction: Self-medication means the use of medications for the treatment of any disease on their own, without consulting any healthcare professional. At times self-medication can be useful if practiced correctly by saving time and money, whereas disadvantages often occur due to lack of evaluation by trained medical professionals and delay ineffective treatment and can result in unnecessary expenses and drug dependence. This study was conducted to find out the self-medication behavior and its associated factors among patients visiting a dental hospital in Kathmandu.
\end{abstract}

Methods: A hospital-based, cross-sectional study was conducted on 265 patients in Kantipur Dental College from December 2019 to January 2020 among the patients attending the dental Out Patient Department. Ethical clearance was obtained from the Institutional Review Committee of Kantipur Dental College. A convenience sampling technique was used. Proformas were prepared in English, translated to Nepali and re-translated to English by the back-translation method. Data entry was done in Microsoft Excel and analysis in SPSS 20. Descriptive statistics was done.

Results: The prevalence of self-medication practice was found to be $166(62.6 \%)$. Out of total participants, 99 (59.6\%) consumed medicines for few days only and the most common triggering factor was found to be toothache in 101 (60.8\%) participants. The most common reason for selfmedication was found to be a previous experience of treating similar illnesses.

Conclusions: The prevalence of self-medication was found to be low as compared to the study done in similar settings. Self-medication practice is a sensitive issue that hasn't been given the required consideration. It is of concern to find every other dental patient being indulged in self-medication whether in the present or the past.

Keywords: oral health; prescription drugs; self medication.

\section{INTRODUCTION}

Self-medication practice means the use of medicines without prescription given by doctors for treating self-recognized conditions. It is an important element of self-care alongside hygiene, nutrition, lifestyle, environmental and socioeconomic factors. ${ }^{1}$ Advantages include saving cost and time while disadvantages include wasting resources, misdiagnosis, drug resistance and interactions etc. ${ }^{2,3}$
In Nepal, drug-stores often are people's first contact point with the healthcare system. ${ }^{4}$ Drugs these days have become more accessible to people. ${ }^{5}$ Many "prescription-only" drugs can be bought over-the-counter (OTC) in developing countries like Nepal. ${ }^{6}$ The most commonly used drug for self-medication worldwide

Correspondence: Dr. Rosina Bhattarai, Department of Community Dentistry, College of Medical Sciences, Bharatpur, Chitwan, Nepal. Email: rosinabhattarai@gmail.com, Phone: +977-9841390383. 
was found to be antibiotics which are also commonly used in dentistry, therefore, necessitating the need for this study. ${ }^{7}$

Many studies have been conducted on self-medication for general illness. However, no studies have been done for dental ailments in Nepal. The present study was conducted to assess the prevalence of self-medication and among patients visiting a dental hospital in Kathmandu.

\section{METHODS}

A hospital-based, descriptive cross-sectional study was conducted in Kantipur Dental College, Teaching Hospital and Research Centre among the patients attending the out-patient department. Convenience sampling technique was used and the required sample size was calculated by using the following formula:

$\mathrm{n}=\mathrm{Z}^{2} \mathrm{XpX} \mathrm{q} / \mathrm{e}^{2}$ where

Where,

$\mathrm{n}=$ sample size

$p=$ prevalence was of self-medication was $81.35 \%$ from the study by Banerjee et al. ${ }^{8}$

$q=1$-p i.e. $18.65 \%$

e $=$ margin of error i.e. $5 \%$

A non-response rate of $10 \%$ was added and the final sample size was calculated to be 265 .

Data collection was done from December 2019 to February 2020. Inclusion criteria included adult patients greater than 18 years of age and those who gave consent for the study. Exclusion criteria included those working in the field of healthcare, those who did not give consent for the study and those who submitted incomplete proformas. Ethical clearance was obtained from the Institutional Review Committee of Kantipur Dental College, Teaching Hospital and Research Centre. The objective of the study was explained and consent was taken from the participants before the study.

The questionnaire was developed by using the study by Komal Raj et al. ${ }^{9}$ and it was validated among 30 patients visiting the hospital. The first section of the questionnaire contained information on the demographic details of the participants. The second section included distance of the respondent's house to the nearest health facility. The third section included questions related to knowledge about self-medication related to oral health problems, triggering factors, reason, the response of people, the source of buying and measures that are taken if the problem persists. The survey proforma was prepared in English which was translated to the Nepali language and re-translated to English by a back-translation method by the faculties of the institute. Data entry was done in Microsoft Excel and analysis was done in SPSS Version 20 software. Descriptive statistics was done where suitable.

\section{RESULTS}

The total participants of the study were 265 with a mean age of 30.46 years. The majority of the participants belonged to the age group of $18-24$ years i.e. $110(41.5 \%)$ and $146(55.1 \%)$ of the participants were females while 119 (44.9\%) were males (Table 1).

\begin{tabular}{|ll|}
\hline $\begin{array}{l}\text { Table 1. Socio-demographic factors of study partic- } \\
\text { ipants. } \\
\text { Characteristics }\end{array}$ & Frequencyn (\%) \\
Gender & $119(44.9)$ \\
Male & $146(55.1)$ \\
Female & \\
Age group & $110(41.5)$ \\
18-24 years & $84(31.7)$ \\
$25-34$ years & $28(10.6)$ \\
$35-44$ years & $30(11.3)$ \\
$45-54$ years & $13(4.9)$ \\
$>55$ years & $144(54.3)$ \\
Marital status & $121(45.7)$ \\
Married & \\
Unmarried & $15(5.7)$ \\
Education & $42(15.8)$ \\
Illiterate & $89(33.6)$ \\
Up to secondary level & $99(37.4)$ \\
Higher secondary level & $20(7.5)$ \\
Bachelors & \\
Masters & \\
\hline
\end{tabular}

The distance between the homes of the majority of the participants and the nearest health center was less than $1 \mathrm{~km}$ (Table 2).

\begin{tabular}{|ll|}
\hline \multicolumn{2}{|l|}{ Table 2. Distance from the nearest health center. } \\
Distance & Frequency $\mathrm{n}(\%)$ \\
$<1 \mathrm{~km}$ & $152(57.4)$ \\
$1-2 \mathrm{~km}$ & $74(27.9)$ \\
$>2 \mathrm{~km}$ & $39(14.5)$ \\
\hline
\end{tabular}

Out of the total 165 participants, the prevalence of self-medication practice among participants was found to be $62.6 \%$.

The duration of self-medication usage by 99 (59.6\%) participants was for few days, triggering factors for the majority of them i.e. 101 (60.8\%) being toothache. Of the total participants, $101(60.8 \%)$ of them had previous experience in treating similar illnesses (Table 3 ). 
Bhattarai et al. Prevalence of Self-medication Practices for Oral Health Problems among Dental Patients in a dental college: A Descriptive...

\begin{tabular}{|ll|}
\hline \multicolumn{2}{|l}{ Table 3. Duration, triggering factors and reasons for } \\
self-medication. & Frequency $\mathrm{n}(\%)$ \\
\hline Questions & $99(59.6)$ \\
Duration of self-medication usage \\
Few days & $16(9.6)$ \\
Few weeks & $51(30.7)$ \\
Till condition subsides & \\
Triggering factor & $101(60.8)$ \\
Toothache & $18(10.8)$ \\
Gum bleeding & $12(7.2)$ \\
Bad breath & $10(6.0)$ \\
Swelling & $20(15.1)$ \\
Others & \\
Reason for self-medication & $46(27.7)$ \\
Lack of time & $7(4.2)$ \\
Lack of money & $101(60.8)$ \\
Previous experience of treat- & \\
ing similar illness & $46(51.8)$ \\
Traditional belief & $52(31.3)$ \\
Unavailability of doctors & $2(1.2)$ \\
Others & $6(3.6)$ \\
Feeling after self-medication & \\
Temporary pain relief & \\
Effective & \\
Useful in stressful condition & $13(3.6)$ \\
Unsure about effects & \\
Curative in nature & \\
Cheaper action & \\
\hline
\end{tabular}

Analgesics are the most widely used drugs by 120 $(72.3 \%)$ of the study participants and the purchase is mostly done in pharmacy shops by $122(73.5 \%)$ (Table 4).

Table 4. Types, sources, and consultation for self-medication and measures taken if the problem persists.

\begin{tabular}{|ll|}
\hline Questions & Frequency $\mathbf{n ~ ( \% ) ~}$ \\
Types of self-medication & \\
Analgesics & $120(72.3)$ \\
Antibiotics & $16(9.6)$ \\
Native herbs & $16(9.6)$ \\
Others & $14(8.4)$ \\
Purchase of medicines from & \\
Pharmacy shop & $122(73.5)$ \\
Hospital pharmacy & $37(22.3)$ \\
Traditional home & $7(4.2)$ \\
Advice is given by &
\end{tabular}

\begin{tabular}{|ll|} 
Relatives & $35(21.1)$ \\
Friends & $23(13.9)$ \\
Personal knowledge & $71(42.8)$ \\
Pharmacist & $30(18.1)$ \\
Mass media & $7(4.2)$ \\
$\begin{array}{l}\text { If problem persists } \\
\text { Visit a dentist }\end{array}$ & $119(71.7)$ \\
$\begin{array}{l}\text { Visit a medical practitioner } \\
\text { Continue with the same } \\
\text { medicine }\end{array}$ & $39(23.5)$ \\
\hline
\end{tabular}

\begin{tabular}{|lc|}
\hline $\begin{array}{l}\text { Table 5. Socio-demographic factors and self- } \\
\text { medication practice. }\end{array}$ & $\begin{array}{l}\text { Prevalence of self-medi- } \\
\text { Characteristics }\end{array}$ \\
$\begin{array}{l}\text { Gender } \\
\text { Male }\end{array}$ & 75 \\
Female & 91 \\
Marital status & \\
Unmarried & 73 \\
Married & 93 \\
Education & \\
Illiterate & 7 \\
Up to secondary level & 23 \\
Higher secondary level & 53 \\
Bachelors & 69 \\
Masters & 14 \\
Age group & \\
18-24 years & 63 \\
$25-34$ years & 58 \\
$35-44$ years & 20 \\
$45-54$ years & 16 \\
$>55$ years & 94 \\
Distance from the nearest health center \\
$<1$ km & 84 \\
1-2 km & 38 \\
$>2$ km & \\
& \\
\hline
\end{tabular}

\section{DISCUSSION}

In the current study, we assessed the self-medication practice among the patients visiting a dental hospital in Kathmandu. The age of the study participants ranged from 18-74 years with the mean age of 30.46 years. The majority of the participants were middle-aged and the prevalence of self-medication was found to be greater among them. This finding is following the study conducted by Shankar et al, 10 and Komal Raj et al. ${ }^{9}$ The reason for this could be because the people of this age-group have knowledge and accessibility to various sources of information and also more workload and in- 
creased stress thereby lesser time to visit a dentist for their treatment needs.

Regarding the duration of self-medication, it was found that majority of the participants i.e. $59.6 \%$ had self-medication practice for few days which was similar to study by Komal Raj et al. ${ }^{9}$ Triggering factor for self-medication was found to be toothache in $60.8 \%$ participants in our study similar to study by Komal Raj et al. ${ }^{9}$ However it was not similar to study by Kalyan et al, ${ }^{11}$ in whom halitosis was found to be more common. The type of medication which was used in most of the participants in our study was analgesics in accordance to study by Kalyan et al, ${ }^{11}$ and Komal Raj et al, ${ }^{9}$ and not similar to studies by Mensah et al, ${ }^{12}$ where the majority of them i.e. $32.1 \%$ use antibiotics and Badiger et $\mathrm{al}^{13}$ where the majority of them use antipyretics during self-medication. Our current study shows participants opting for self-medication practice due to previous experience of treating similar illness which is contrary the to the study by Komal Raj et al, ${ }^{9}$ in which the majority of the participants took advice from the pharmacist.

The prevalence of self-medication practice was found to be $62.6 \%$ in our study which is in accordance to study by Baig et al, ${ }^{14}$ which was found to be $57.3 \%$ and more compared to study by Kassie et al, ${ }^{2}$ where prevalence was $35.9 \%$. The study by Komal Raj et al, 9 showed a very high prevalence of self-medication practice i.e. $100 \%$ which may be due to various reasons like distance from the nearest health center, time factor or the belief in the clinical efficacy of traditional herbs. The majority of the participants $(73.5 \%)$ purchase the medicine from the pharmacy based on their knowledge
$(42.8 \%)$ followed by instructions from relatives and pharmacists. The present study shows that there is a growing trend of self-medication practice. Owing to the various adverse reactions and side effects, the supply of medicines without a valid prescription should be prohibited.

\section{CONCLUSIONS}

The prevalence of self-medication was found to be low as compared to the study done in similar settings. Self-medication practice is a sensitive issue that hasn't been given the required consideration. It is of concern to find every other dental patient being indulged in self-medication whether in the present or the past. It is the responsibility of the dental practitioner to create awareness among their patients about the various hazards of self-medication.

This can be done on an individual level as well as through various professional organizations. Also, proper control measures of dissemination of medicines and rational restriction of the availability of medicines to the public without prescription should be promoted.

\section{ACKNOWLEDGEMENTS}

We would like to acknowledge all the patients attending the hospital who participated in our study and Kantipur Dental College for their cooperation and support.

\section{Conflict of Interest: None.}

\section{REFERENCES}

1. Organization WH. Responsible self-care and self-medication; A worldwide review of consumers' survey; the World Self-Medication Industry. 2010.

2. Kassie AD, Bifftu BB, Mekonnen HS. Self-medication practice and associated factors among adult household members in Meket district, Northeast Ethiopia, 2017. BMC Pharmacol Toxicol; 2018;4-11. [ $\underline{\text { PubMed }|~ F u l l ~ T e x t ~| ~ D O I] ~}$

3. Lei X, Jiang H. Self-Medication Practice and Associated Factors among Residents in Wuhan, China. Int J Env Res Public Heal. 2018;15(2):68. [uㅏMed | Full Text | DOI]

4. Kafle KK, Madden JM, Shrestha AD, Karkee SB, Das PL, Pradhan YMS, et al. Can licensed drug sellers contribute to safe motherhood? A survey of the treatment of pregnancy-related anaemia in Nepal. Soc Sci Med. Pergamon; 1996 Jun;42(11):1577-88. [PubMed | Full Text | $\underline{\mathrm{DOI}}]$
5. Jain S, Malvi R, Purviya JK. Concept of self-medication: A review. Int J Pharm Biol Arch. 2011;2(3):831-6. [Full Text]

6. Chang F, K. Trivedi P. Economics of self-medication: theory and evidence. Health Econ. Wiley Online Library; 2003;12(9):721-39. [릴ed | Full Text | DOI]

7. Cars O, Hogberg LD, Murray M, Nordberg O, Sivaraman $\mathrm{S}$, Lundborg CS, et al. Meeting the challenge of antibiotic resistance. BMJ. 2008;337:a1438. [uㅏbMed | Full Text | DOI]

8. Banerjee I, Sathian B, Gupta RK, Amarendra A. Self-medication practice among preclinical university students in a medical school from the city of Pokhara, Nepal. Nepal J Epidemiol. 2016;6(2):574-81. [PubMed | Full Text | $\underline{\mathrm{DOI}}]$ 
9. Komalraj MR, Bhat PK, Aruna CN. Self-medication Practices for Oral Health Problems among Dental Patients in Bangalore: A Cross Sectional Study. J Pharm. 2015;5(10):68-75. [Full Text]

10. Shankar PR, Partha P, Shenoy N. Self-medication and non-doctor prescription practices in Pokhara valley, Western Nepal: a questionnaire-based study. BMC Fam Pract. 2002;3(1):17. [PubMed | Full Text | DOI]

11. Kalyan VS, Sudhakar K, Srinivas P, Sudhakar GV, Pratap KV, Padma TM. Evaluation of self-medication practices among undergraduate dental students of tertiary care teaching dental hospital in South India. J Educ Ethics Dent. 2013;3(1):21-5. [Full Text]
12. Mensah BN, Agyemang IB, Afriyie DK, Amponsah SK. Self-Medication Practice in Akuse, a Rural Setting in Ghana. Niger Postgrad Med J. 2019;26(3):189-94. [ㄹuMed | Full $\underline{\text { Text }}$ | DOI]

13. Badiger S, Kundapur R, Jain A, Kumar A, Pattanshetty $\mathrm{S}$, Thakolkaran $\mathrm{N}$, et al. Self medication patterns among medical students in South India What this study adds: Australas Med J. 2012;5(4):217-20. [ $\underline{\text { PubMed } \mid ~} \underline{\text { Full Text }}$ | DOI]

14. Baig Q Ali, Muzaffar D, Afaq A, Bilal S, Iqbal N. Prevalence of self-medication among dental patients. Pakistan Oral Dent J. 2012;32(2):292-5. [․ull Text] 